\title{
Marie Stopes International's SIFPO Project-Strengthening international family planning organizations, October 2010-September 2015
}

Population Council

Follow this and additional works at: https://knowledgecommons.popcouncil.org/departments_sbsr-rh

Part of the Demography, Population, and Ecology Commons, Family, Life Course, and Society Commons, International Public Health Commons, and the Women's Health Commons How does access to this work benefit you? Let us know!

\section{Recommended Citation}

Population Council. 2015. "Marie Stopes International's SIFPO Project-Strengthening international family planning organizations, October 2010-September 2015." Nairobi: Population Council. 
MARIE STOPES INTERNATIONAL'S SIFPO PROJECTSTRENGTHENING INTERNATIONAL FAMILY PLANNING ORGANIZATIONS

October 2010 - September 2015 COUNCIL 


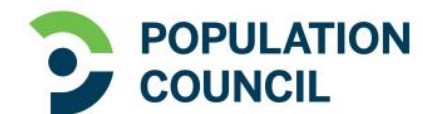 \\ Ideas. Evidence. Impact.}

The Population Council confronts critical health and development issues-from stopping the spread of HIV to improving reproductive health and ensuring that young people lead full and productive lives. Through biomedical, social science, and public health research in 50 countries, we work with our partners to deliver solutions that lead to more effective policies, programs, and technologies that improve lives around the world. Established in 1952 and headquartered in New York, the Council is a nongovernmental, non-profit organization governed by an international board of trustees.

Population Council

General Accident House

Ralph Bunche Road

Nairobi, Kenya

Tel: 254202713480

popcouncil.org

Suggested citation: Population Council. 2015. Final Report: Marie Stopes International's SIFPO ProjectStrengthening International Family Planning Organizations. Nairobi: Population Council. 


\section{Table of Contents}

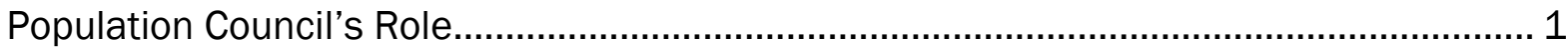

Activity 1.1.3. External evaluations of outreach service delivery in selected countries ..... 2

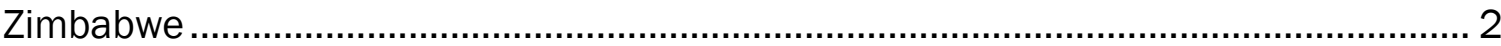

India

Activity 1.2.4. External evaluations of innovative approaches for addressing financial barriers to services and efficient pricing............................................................................. 4

Improved understanding of performance-based financing .......................................... 4

Review of the literature of performance-based incentives for community-based family planning programs .............................................................................................. 4

A pilot pay-for-performance model in Uganda ........................................................... 4

Vouchers within a social franchising program in Uganda ............................................ 5

Willingness-to-pay study in Burkina Faso ................................................................. 5

Activity 1.3.1. Establish SIFPO-MSI Technical Leadership Group ..................................... 6

Activity 2.1.2. Peer review of MSI's quality of care framework and M\&E indicators .......... 7

Activity 2.1.3. Regional training for research and evaluation skills building...................... 7 


\section{List of Abbreviations}

$\begin{array}{ll}\text { CHW } & \text { Community health worker } \\ \text { CPR } & \text { Contraceptive prevalence rate } \\ \text { EC } & \text { Emergency contraception } \\ \text { FP } & \text { Family planning } \\ \text { GBV } & \text { Gender-based violence } \\ \text { Gol } & \text { Government of India } \\ \text { HIV } & \text { Human Immunodeficiency Virus } \\ \text { ICRW } & \text { International Center for Research on Women } \\ \text { IUD } & \text { Intrauterine device } \\ \text { M\&E } & \text { Monitoring and evaluation } \\ \text { MSI } & \text { Marie Stopes International } \\ \text { MSU } & \text { Marie Stopes Uganda } \\ \text { P4P } & \text { Pay for performance } \\ \text { PBI } & \text { Performance-based incentive } \\ \text { PSZ } & \text { Population Services Zimbabwe } \\ \text { RH } & \text { Reproductive health } \\ \text { SIFPO } & \text { Strengthening International Family Planning Organizations } \\ \text { SRH } & \text { Sexual and reproductive health } \\ \text { STI } & \text { Sexually transmitted infection } \\ \text { TLG } & \text { Technical leadership group } \\ \text { USAID } & \text { United States Agency for International Development } \\ \text { VHT } & \text { Village health team } \\ \text { WtP } & \text { Willingness to pay } \\ & \end{array}$




\section{Population Council's Role}

The Population Council was a partner in the Strengthening International Family Planning Organizations (SIFPO) Project implemented by Marie Stopes International (MSI). SIFPO-MSI's mandate was increasing use of voluntary family planning (FP) services globally by strengthening selected international FP organizations with global reach and an extensive, multi-country network of FP clinics for achieving maximum program impact and synergies.

Within the SIFPO-MSI consortium, Population Council's original role was to:

- Evaluate the effectiveness of MSI's FP programs to identify successful best practices and approaches, through operations research and other evaluations;

- Assist MSI to disseminate the findings of some or all of the evaluations, which could include co-hosting symposia for both generating broad discussion of the findings and disseminating evaluation results, with the Council also utilizing its dissemination vehicles, such as its journals, publications, seminars, web site, and other means as appropriate;

- Strengthen MSl's internal research and metrics capacity with thematic workshops on research methodologies for MSI research staff based regionally and in MSI country programs;

- Co-host, with MSI, a "community of practice" event or events on FP metrics convening other FP community stakeholders to agree on a common set of metrics for program effectiveness and impact;

- Provide advice, and potentially research, along with other MSI SIFPO partners and consultants, for designing, supporting, and enhancing integration efforts in MSI service delivery activities to link FP with HIV, and with other reproductive health $(\mathrm{RH})$ services;

- Provide links with relevant Population Council research and forums by leveraging resources from similar activities.

In response to rapidly evolving contexts during the life of the project, and in conjunction with SIFPO-MSI leadership, activities during this five year period comprised:

- Activity 1.1.3. External evaluations of outreach service delivery in selected countries

- Activity 1.2.4. External evaluations of innovative approaches for addressing financial barriers to services and efficient pricing

- Activity 1.3.1. Establish SIFPO-MSI Technical Leadership Group

- Activity 2.1.2. Peer review of MSl's quality of care framework and monitoring and evaluation indicators

- Activity 2.1.3. Regional training on research and evaluation skills building

Population Council would like to acknowledge MSI's excellent management of this consortium, as well as the high quality and sustained technical engagement provided for all of the Council's activities. 


\section{Activity 1.1.3. External evaluations of outreach service delivery in selected countries}

In partnership with MSI, Population Council designed and conducted external evaluations of mobile outreach service delivery programs in two countries-one in Africa, Zimbabwe-and one in Asia, India-for examining counseling service quality, effectiveness of follow up mechanisms enabling use continuation, and suggesting improvements for structure and delivery of FP packages.

\section{ZIMBABWE}

Zimbabwe's fertility rate is 4.1 children per woman, and its contraceptive prevalence rate (CPR) is 59 percent, with 73 percent of all women using modern contraceptive methods obtaining them from the public sector. Integration of other services, including HIV, into sexual and reproductive health (SRH) services is outlined in the National Strategic Plan. Eight Population Services Zimbabwe (PSZ) teams currently provide mobile outreach services in over 500 sites in eight of the country's nine provinces. The mobile teams complement the Government's facility-based services and offer pills, condoms, emergency contraception (EC), injectables, implants, intrauterine devices (IUDs), tubal ligation, and vasectomy.

In four provinces Population Council assessed multiple components of service quality, including information and counseling on methods and services, clinical procedures and adverse event occurrences, client health-seeking behaviors, and client satisfaction; integration of HIV and gender-based violence (GBV) services were also documented. In September and October 2013, 665 women receiving tubal ligation (1\%), implant (92\%), or IUD (7\%) services were recruited at high volume mobile outreach sites. Data collection involved observations of client and provider interactions and service provision, as well as client interviews immediately following service, on the day of the procedure. Clients were then asked to return 15 days post-procedure, when they were interviewed about any adverse events and their health-seeking behaviors.

The median client age was 26 years old; 43 percent had a child under one year old, and 40 percent reported planning to have a child "more than five years from now." Most women had primary or secondary educations. Thirty nine percent of clients had discussed FP with their partner or spouse, and 95 percent reported testing for HIV at some prior time, while 24 percent reported unprotected sex within the last three months.

All clients received information on their chosen method's risks and benefits, along with the risks and benefits of condoms. Sixty-one percent of clients were provided HIV/AIDS counseling, while 58 percent were asked about sexually transmitted infections (STIs). Ninety four percent of clients were asked about their obstetric histories, and 62 percent were provided gynecology, obstetrics, or breast cancer information. GBV was discussed in 12 percent of sessions. In the exit interviews 95 percent of clients reported provider instructions on side effects management. Many contraceptive method misconceptions persist even after group education and counseling, such as: women who have never had a baby cannot use an IUD or DMPA, IUDs cause partner discomfort during sex, hormonal contraceptives can cause cancer, and pills can make a woman sterile.

At the Day 15 follow up, 91 percent of clients were interviewed about their experiences of side effects and whether they sought care, with 65 percent of those interviewed reporting symptoms at some point, on the day of procedure, and through and including Day 15, with most reporting expected side effects on the procedure day; 32 percent experienced a side effect until Day 15, with most either "very mild" or "mild," and expected side effects of the FP method or procedure. No serious complications were reported; 24 clients (4\%) experienced a side effect requiring treatment, and of those one half called PSZ's helpline, and one half of those who called the helpline returned to their facility and were seen by a provider prior to Day 15.

Eight clients 
experienced constant temperature or fever and returned to the health facility for removal of the method; five of these clients reported satisfaction with their follow up treatment.

The evaluation recommended: i) stronger integration of HIV and other STI counseling, testing, and condom promotion that could provide an opportunity to intensify infection prevention among FP clients; ii) efforts to reach male partners through the outreach program that could enhance messages about infection prevention and enable greater support for women's FP use; iii) providers need to focus on correcting myths and misconceptions associated with each contraceptive method during group and individual counseling. Study findings were shared by PSZ and Council staff, for discussion with national stakeholders, including USAID, in a half day workshop in Harare on October $29^{\text {th }}, 2014$. The meeting endorsed the recommendations.

\section{INDIA}

India has a modern CPR of 48 percent, and one in five married women has an unmet need, especially in remote rural areas. Currently, nearly three quarters (71\%) of modern method FP users in India choose female sterilization, and only two percent of women use the IUD; the contraceptive implant is not yet registered in India. Although the Government of India (Gol) has been actively delivering tubal ligation through outreach, its capacity is limited and a significant demand for tubal ligation and IUD in rural area remains unmet. Marie Stopes India implements a mobile outreach program to increase access to IUDs, tubal ligation, and vasectomy. In 2011, MS India provided 32 percent of all tubal ligations and eight percent of all IUDs in the state of Rajasthan.

Population Council evaluated MS India's mobile outreach services for better understanding safety, acceptability, and the profiles of clients accessing contraceptive services. The study focused on tubal ligation and IUD procedures in four Rajasthan districts. Between March and October 2012, 875 women receiving a tubal ligation and 402 women receiving an IUD procedure were recruited for the study. Clients were interviewed before and immediately after their procedure at the outreach site, and on Day 15 post-procedure, about their side effects and satisfaction. Women using an IUD were also interviewed at Day 90 about discontinuation and switching.

The majority of women were from rural areas (81\% of TL clients; $72 \%$ of IUD clients), poor households and had no education (53\% of TL clients; $30 \%$ of IUD clients), which shows that through this service MS India is also fulfilling its objective in reaching underserved women in rural settings. Before taking up a FP method from MS India mobile outreach, 63 percent of tubal ligation clients and 41 percent of IUD clients had never used modern contraception.

The study demonstrated that tubal ligation and IUD procedures can be provided safely and effectively in rural and hard to reach areas of Rajasthan through MS India's mobile outreach approach. No major complications were reported among the women sampled, and side effects were generally mild or moderate. One third of tubal ligation and IUD users reported some side effects following the procedure. By Day 15, one quarter of IUD users and 15 percent of tubal ligation users reported still experiencing a mild or moderate side effects; four IUD users and one user reported a severe complication (pain, bleeding, abdominal pain or swelling.). By Day 90, eight percent of women had discontinued the IUD, which is relatively high; moreover, only half of these switched to another method. Among the women continuing with the method, 46 percent reported experiencing side effects through until Day 90.

These findings recommend that FP programs serving rural India should consider mobile outreach models to complement the method mix available in Gol facilities. Attention needs to be paid to reducing unwanted IUD discontinuation during the first three months and enhancing opportunities for switching to prevent unintended pregnancy. The study findings were shared with over 40 national stakeholders in a September $25^{\text {th }}, 2013$ New Delhi workshop that reviewed a range of alternative approaches for "reaching the unreached" with FP services. 


\section{Activity 1.2.4. External evaluations of innovative approaches for addressing financial barriers to services and efficient pricing}

Accessibility to FP services is partially determined by costs prospective clients face. One important cost structure component, among many, is the salary and reimbursement fees for clinicians and other health care staff, including pay for performance (P4P) schemes. Another is pricing used to sell commodities and services, and client willingness and ability to pay. During the first year, Population Council undertook two activities.

\section{IMPROVED UNDERSTANDING OF PERFORMANCE-BASED FINANCING}

Population Council convened a meeting in Nairobi, Kenya on June $28^{\text {th }}$ and $29^{\text {th }} 2011$ to address financial barriers and improve the efficiency of pricing for community health worker (CHW) programs. The meeting convened MSI staff from Ghana, Kenya, Malawi, Pakistan and Uganda, and featured resource persons from Population Council, MSI and the USAID-supported Health Systems 20/20 Project. The meeting report summarizes the issues discussed and identifies the need for both a review of the larger literature on a variety of performance-based financing mechanisms specifically for FP services, as well as better understanding of MSI affiliates' current design and implementation of P4P and other performance-based financing models for recommendations of best practices, for MSI and other organizations.

\section{REVIEW OF THE LITERATURE OF PERFORMANCE-BASED INCENTIVES FOR COMMUNITY-BASED FAMILY PLANNING PROGRAMS}

The Council rigorously reviewed the published and grey literature on experiences with performance-based incentives (PBIs) in community FP programs. A total of 29 programs in 22 countries in Asia, Africa, and Latin America were identified. The most common type of PBI was a per unit sales commission for FP products sold by community-based distributors. Another common PBI model was a payment for FP referrals to clinics, typically focused on long term FP methods. Other models used a bonus system, with a base salary augmented with payments based on performance.

Six studies were identified that specifically evaluated the impact of PBIs on community-based FP program performance. They found mixed results on the benefits of PBIs, but indicated that easily understood PBIs are more effective than complicated schemes. Considerations for designing PBIs for community-based FP programs include: incentives sufficient for encouraging increased utilization without coercion; incentives not creating preferences for one type of FP but respecting the principles of informed choice; and cost-efficient PBIs compared to other types of FP programs. Further research is needed about whether PBIs embedded in community-based FP programs are effective in improving FP delivery and reducing its unmet need. A resultant paper was published in a peer-reviewed journal, and an oral presentation was given at the International Family Planning Conference in Ethiopia in November 2013.

\section{A PILOT PAY-FOR-PERFORMANCE MODEL IN UGANDA}

Marie Stopes Uganda (MSU) provides approximately one quarter of all FP services in Uganda, usually in underserved areas with lowest CPRs, and prioritizes initial FP users. Village Health Teams (VHTs) link communities to health facilities, and VHT workers act as CHWs. MSU's three types of referral systems utilize CHWs, who discuss FP with women in their communities and then refer interested women to a facility. Each 
referral system is characterized by a different PBI form, or P4P model, to motivate CHWs' discussions of FP and referrals of those interested in FP counseling at a facility. In collaboration with MSU staff, the Council documented MSU's experiences with these P4P models to better understand their experiences incentivizing CHWs with PBIs to more effectively make referrals for those women who want to learn more about FP.

The assessment revealed some difficulties with the intervention's planned implementation; additional data analyses resulted in recommendations that MSU make further efforts to compensate VHTs using a P4P approach, with continued research on the effectiveness and consequences of a P4P strategy.

\section{VOUCHERS WITHIN A SOCIAL FRANCHISING PROGRAM IN UGANDA}

Between 2011 and 2014, MSI integrated a FP voucher scheme within its social franchise program in Uganda by training and supporting 400 private facilities throughout the country to provide high quality FP counseling and selected FP methods in a partial franchise model. To reduce financial barriers, a subsidized voucher was introduced specifically for poor women, who could redeem it for a FP service of their choice at an accredited private provider. Although the voucher was intended primarily for increasing access to implants, IUDs and tubal ligation, it was also redeemable for short acting methods. Providers were reimbursed by MSI.

The study used routine data from clients for describing service trends, voucher client demographics, and estimates of the program's contribution in reducing unmet FP need and increasing CPR. During the study period, 282,880 women received FP voucher services, of which 57 percent were not previously using any FP method; 71 percent of clients used their voucher for an implant, and 24 percent for an IUD. The franchising with voucher model added an average of 94,300 new LARC users per year from 2011 to 2014.

Voucher monitoring data also offer opportunities for quality improvement interventions. Most voucher clients initially chose implants, but a 2013 voucher client follow up survey's results indicate many clients were not fully counseled on IUDs and that franchisees lacked confidence in IUD counseling and provision. After retraining and mentoring providers, IUD provision rose from 12 percent of LARCs in 2012 to 30 percent in 2014. Findings from this study will be shared in a FP voucher panel session at the International Family Planning Conference in November 2015, and a paper will be submitted to a peer-reviewed journal.

\section{WILLINGNESS-TO-PAY STUDY IN BURKINA FASO}

Council staff collaborated with London MSI staff and MSI and Council staff in Burkina Faso to design a Willingness to Pay (WtP) study, with USAID engagement from its West Africa regional office in Accra. This study began in December 2012, after ethical approval from Burkina Faso's national IRB and the Council's IRB. Data were collected, processed, and analyzed from January to April 2012, and the draft report was prepared in May and June 2012. This study collected data from $45 \mathrm{MSI}$ sites (one static clinic and 44 outreach sites) in eight health districts. WtP and client satisfaction were determined for three FP methods-tubal ligation, implants, and IUD-in client exit interviews that adhered to a previously validated methodology for estimating WtP. Altogether, 1,772 clients were interviewed: 306 at the clinic and 1,466 at outreach sites. Implant users accounted for 46 percent, and IUD users 35 percent, of the interviewees. One third of clients were under 24 years of age, most (93\%) were married or in a union, and half were farmers while one third were housewives or unemployed. The principal information source was radio (42\%), and 82 percent had no formal education. One third of clients earned less than $\$ 1.25$ per day. One half of clients learned of MSI from another client, with low cost (59\%), good reputation (23\%), and proximity (15\%) constituting the primary reasons for choosing MSI.

Clients were asked about their satisfaction with hours of operation, cleanliness, waiting times, service costs, service quality, client reception, staff discretion, consultation duration, and acceptability of services or care. For all aspects, over 90 percent of respondents were either satisfied or very satisfied. When asked about their willingness to pay, most $(80 \%)$ indicated willingness to pay the highest increment proposed over the current price. From this analysis MSI has determined a new pricing structure for services both at its outreach sites and the clinic, which should increase its income while sustaining at least 90 percent of current client load, thereby enhancing sustainability. 


\section{Activity 1.3.1. Establish SIFPO-MSI Technical Leadership Group}

The SIFPO-MSI Technical Leadership Group (TLG) comprised representatives from Population Council, the International Center for Research on Women (ICRW), EngenderHealth, and the International HIV/AIDS Alliance. Population Council staff attended the SIFPO-MSI consortium inaugural meeting on January $12^{\text {th }}, 2011$ in Washington, DC, where terms of reference for the TLG were drafted. Population Council staff attended all

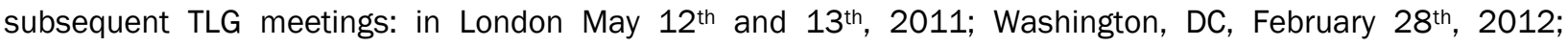
Washington, DC, November 29th and 30th 2012 ; and May 20th 2014 remotely. Council staff also attended and made a presentation (on the mobile outreach evaluations) at the SIFPO End of Project Conference in Washington, DC, on September $18^{\text {th }}, 2015$. 


\section{Activity 2.1.2. Peer review of MSl's quality of care framework and monitoring and evaluation indicators}

When the SIFPO-MSI project began, MSI's conceptual framework for its Monitoring and Evaluation system required further elaboration for consistent application in country programs. During SIFPO's first year, Population Council reviewed existing materials and systems for defining, assessing, and assuring quality of care. The review resulted in a particularized conceptual framework based upon the globally-accepted Bruce-Jain framework and incorporating MSI's existing systems and procedures, and recommended actionable items for potential advocacy for institutional emphasis on quality of care. A document summarizing the review's findings and lessons was prepared and submitted to MSI and USAID.

\section{Activity 2.1.3. Regional training for research and evaluation skills building}

At the request of MSI, Population Council designed and led a workshop on operations research and evaluation for selected MSI headquarters and country research staff and program managers. An agenda with training and resource materials was prepared by the Council and MSI organized the five day workshop, in Nairobi, Kenya April $11^{\text {th }}$ through 15th, 2011. 



\section{POPULATION COUNCIL}

Ideas. Evidence. Impact.

popcouncil.org 